University of Nebraska - Lincoln

DigitalCommons@University of Nebraska - Lincoln

Faculty Publications, Department of Psychology

Psychology, Department of

March 1990

\title{
Ecology of Depression in Late Childhood and Early Adolescence: A Profile of Daily States and Activities
}

\author{
Reed Larson \\ University of Illinois and Michael Reese Hospital, larsonr@ad.uiuc.edu \\ Marcela Raffaelli \\ University of Nebraska-Lincoln, mraffaelli1@unl.edu \\ Maryse H. Richards \\ Loyola University of Chicago \\ Mark Ham \\ University of Chicago \\ Lisa Jewell \\ Loyola University of Chicago
}

Follow this and additional works at: https://digitalcommons.unl.edu/psychfacpub

Part of the Psychiatry and Psychology Commons

Larson, Reed; Raffaelli, Marcela; Richards, Maryse H.; Ham, Mark; and Jewell, Lisa, "Ecology of Depression in Late Childhood and Early Adolescence: A Profile of Daily States and Activities" (1990). Faculty Publications, Department of Psychology. 196.

https://digitalcommons.unl.edu/psychfacpub/196

This Article is brought to you for free and open access by the Psychology, Department of at DigitalCommons@University of Nebraska - Lincoln. It has been accepted for inclusion in Faculty Publications, Department of Psychology by an authorized administrator of DigitalCommons@University of Nebraska - Lincoln. 
Published in Journal of Abnormal Psychology, Vol. 99, No. 1 (1990), pp. 92-102. Copyright (C 1990 by the American Psychological Association, Inc. Used by permission. "This article may not exactly replicate the final version published in the APA journal. It is not the copy of record." http://www.apa.org/journals/abn/

\title{
Ecology of Depression in Late Childhood and Early Adolescence: A Profile of Daily States and Activities
}

\author{
Reed W. Larson, University of Illinois and Michael Reese Hospital \\ Marcela Raffaelli, University of Chicago and Michael Reese Hospital \\ Maryse H. Richards, Loyola University of Chicago \\ Mark Ham, University of Chicago \\ Lisa Jewell, Loyola University of Chicago
}

\begin{abstract}
This study investigated daily states and time use patterns associated with depression. Four hundred eighty-three 5th to 9th graders reported on their experience when signaled by pagers at random times. Depressed youth reported more negative affect and social emotions, lower psychological investment, lower energy, and greater variability in affect. These differences were weaker for 5th and 6th graders, suggesting that self-reported feeling states are a poor indicator of depression prior to adolescence. No differences were found in the daily activities of depressed youths nor in the amount of time spent alone, but depressed youths experienced other people as less friendly and more often reported wanting to be alone, especially when with their families. They also spent less time in public places and more time in their bedrooms. Finally, depressed boys, but not girls, spent much less time with friends, particularly of the same sex, suggesting that social isolation is more strongly associated with depression for boys.
\end{abstract}

Depression is diagnosed as a condition of psychological maladjustment to daily life. Diagnostic schemes, such as the revised third edition of the Diagnostic and Statistical Manual of Mental Disorders (DSM-III-R, American Psychiatric Association, 1987), identify cardinal symptoms that include distinct patterns of daily behavior (e.g. social isolation) and a list of psychological states (depressed mood, low energy, poor concentration, loss of interest in normal activities, feelings of fatigue, psychomotor agitation, and a sense of worthlessness) presumed to permeate much of a person's waking hours. Although there is an increasing recognition that depression may be expressed differently in childhood and adolescence than in adulthood (Carlson \& Garber, 1986; Rutter, 1986), these features of daily behavior and psychological ex-

An earlier version of this article was presented at the meetings of the Society for Research in Child Development in Kansas City, Missouri on April 27-30, 1989.

This research was supported by National Institute of Mental Health (NIMH) Grant 1 RO1 MH38324, "Stress in Daily Life During Early Adolescence," awarded to Reed Larson and carried out through Michael Reese Hospital and Medical Center.

We wish to thank Claudia Lampman-Petraitis, Alicia Joebgen, Mary Chandler, and Linda Asmussen for assistance with the data analyses. This article was written while Marcela Raffaelli was a predoctoral fellow in the Clinical Research Training Program in Adolescence, jointly sponsored by Michael Reese Hospital and the University of Chicago (under NIMH Grant MH 14668).

Correspondence concerning this article should be addressed to Reed Larson, Division of Human Development \& Family Ecology, University of Illinois, 1105 West Nevada Street, Urbana, Illinois 61801. perience are included in most classifications of childhood depression (McConville \& Bruce, 1985).

Existing knowledge on the daily manifestation of depression among children and adolescents, however, is limited. A fundamental problem is that nearly all of our current information on the expression of childhood depression is based on data obtained from interviews or questionnaires administered at one point in time within a clinic or research context. Such information lacks "ecological validity" and is subject to the bias and distortion of recall (Bernard, Killworth, Kronenfeld, \& Sailer, 1984). Kovacs (1986) summarizes evidence indicating that children of elementary school age make substantial errors in ordering and estimating the duration of past events and describe themselves only in terms of the immediate present. Although these findings do not warrant abandoning one-time questionnaire and interview measures, they do indicate a need for research using more direct measures of immediate experience.

To investigate the daily ecology of depression, in this study we obtained time-sampling data on the hour-to-hour moods, companionship, and activities of students in fifth to ninth grade who were selected randomly from a general, nonclinical population. The 406 participants were differentiated for these analyses according to depression scores obtained from the Children's Depression Inventory (CDI; Kovacs, 1985; Kovacs \& Beck, 1977). Because these data are immediate, they circumvent problems associated with recall. It is generally recognized that by late childhood, children are capable of labeling affective states (Kovacs, 1986; Schwartz \& Trabasso, 1984); how adequately depressed 
children use this capability is an unresolved question (Carlson \& Garber, 1986; Kovacs, 1986) that is partly addressed by this investigation.

Prior research establishes some general expectations that guided our analyses of the data. Two previous studies dealt directly with emotional states. Izard and Schwartz (1986), using retrospective accounts, found depression to be associated with differential experience of a wide range of emotional states in children and adolescents. Merrick (1988), using the same time- sampling technique used here, found lower and more variable affect in a sample of 7 clinically depressed 12-17-year-olds compared with in a control sample of nondepressed teenagers. Both studies call attention to the issue of variability. Curiously, the third edition of the Diagnostic and Statistical Manual of Mental Disorders (DSM-III, American Psychiatric Association, 1980 - but not DSM-III-R) suggested that depressed adolescent boys may show increased emotionality, but was silent about girls. Izard and Schwartz (1986), on the other hand, reported a wider range of emotional states among depressed college-aged girls than among their depressed male peers.

Other research supports the inference that disturbed psychological states among depressed children and adolescents may be particularly acute in specific social contexts. Studies show that depressed youngsters experience poorer relationships with their families (Asarnow, Carlson, \& Guthrie, 1987; Burbach \& Borduin, 1986; Kashani, Beck, et al., 1987), decreased peer interaction (Kandel \& Davies, 1982; Lefkowitz \& Tesiny, 1980; Quay \& LaGreca, 1986), and diminished school performance (Inamder, Simopoulos, Osborn, \& Bianchi, 1979; Quay \& LaGreca, 1986). Depressed states might vary across these contexts, or they might be generalized across all contexts.

We also were led to expect that patterns of depression may differ as a function of age and gender. The diagnosis of depression in prepubescent children is relatively new, and the profile of symptoms in this age period remains ill-defined (Garber, 1984; Rutter, 1986). With the onset of adolescence, however, changing environmental press and developing cognitive capabilities are hypothesized to alter and broaden the range of defining features (Gove \& Herb, 1974; Petersen, Ebata, \& Sarigiani, 1987; Rutter, 1986).

Differentiation between genders represents one of the clearest effects of age. Studies of clinical and nonclinical populations find that after the age of about 13, depression is much more common among girls than among boys (Izard \& Schwartz, 1986; Kandel \& Davies, 1982; Kashani, Beck, et al., 1987; Kashani, Carlson, et al., 1987; Nelson, Politano, Finch, Wendel, \& Mayhall, 1987; Webb \& VanDevere, 1985). Patterns of symptoms also have been found to diverge between the sexes, foreshadowing well-established adult differences in the expression of depression (NolenHoeksema, 1987). Depressed girls show more disturbed affect and internalizing behavior (Webb \& VanDevere, 1985), whereas depressed boys show more externalizing behavior (Gjerde, Block, \& Block, 1988; Puig-Antich, 1982). Coping mechanisms also differ-depressed women tend to confide in a friend or seek professional help, whereas men tend to ignore their problems or abuse substances (Nolen-Hoeksema, 1987; Vredenburg, Krames, \& Flett, 1986) — and these differences may lead to contrasting daily patterns of affect and behavior.
The current study, then, investigates how depressed and nondepressed youngsters represent their daily psychological experiences and examines how these representations vary by age, by sex, and across the various contexts of the youngsters' daily lives. The period from fifth to ninth grade covered by this study bridges the transition from childhood to adolescence and thus is suited to identification of these age and age-by-sex differences in the manifestation of depression. We also examine differences in external aspects of the daily lives of depressed and nondepressed youths, including what they do, where they go, who they spend their time with, and what they think about-elements of the daily ecology that may also provide important information about psychological disorders (deVries, 1987). Normative age trends for these data are presented in other publications (Larson \& Lampman-Petraitis, 1989; Larson \& Richards, in press).

Several qualifications should be kept in mind. First, the study deals with a nonclinical, random population of children and young adolescents; second, it relies on a single, self-report instrument to identify levels of depression. Thus, in many cases we may be dealing with subclinical levels of depression-that is, with depressive tendencies and dysthymia, rather than major depression. Nonetheless, there is evidence that depressive tendencies are continuous with major depressive disorders (Blatt, D'Afflitti, \& Quinlan, 1976; Hirschfeld \& Cross, 1982) and that individuals who manifest depression early in life develop clinical depression or other psychological problems later on (Kandel \& Davies, 1986; Kovacs, Feinberg, Crouse-Novack, Paulauskas, \& Finkelstein, 1984; Petersen et al., 1987; Strober \& Carlson, 1982).

\section{Method}

\section{Sample}

The sample consists of 406 randomly selected fifth to eighth graders (ages 10 to 15) stratified by gender, school grade, community, and time of year of participation. The fifth to eighth graders in the sample were selected from the populations of four Chicago-area schools, two in a working class community on the edge of the city and two in an outlying white-collar suburb. The ninth graders were selected from the high schools serving the same residential neighborhoods. Participation of .different students occurred across the four seasons of the year. All students were White. (The study was conducted in eight waves with a total of 483 students. Seventy-seven students from the first two waves of data collection are not included in these analyses because the CDI was not included at that point.)

The final sample of 406 includes $70 \%$ of the randomly selected students initially invited to take part in the study. Of those invited, $124(24 \%)$ elected not to participate or did not participate because their parents refused to give them permission, and $35(6 \%)$ took part in the study but provided data that were deemed unusable. Nonparticipation was not related to sex, grade, or community, but was more frequent for students invited to take part during the summer. An anonymous survey of all of the students in two of the schools, conducted after the study, showed that the students who took part in the study were not significantly different from the school population in self-esteem or socioeconomic status (SES) ratings of parents' occupations. There was, however, a lower refusal rate among students in single parent families and a higher refusal rate among students in families where parents were remarried. A sociometric survey conducted in one of the schools also showed

\footnotetext{
${ }^{1}$ The study was conducted in eight waves with a total of 483 students. Seventy-seven students from the first two waves data collection are not included in these analyses because the CDI was not included at that point.
} 
that participants in the study were not different from the school population in peer popularity. The 35 students who provided unusable data were not significantly different from the final sample in their CDI scores, but had lower self-esteem and lower school grade point averages (see Larson, in press, for further description of the sample and the study).

\section{Procedures}

The study was administered through the students' schools. All contacts took place during school hours. Participants in the study carried electronic pagers and a booklet of self-report forms for 1 week. Their instructions were to fill out one self-report form in response to each signal received via the pagers, following the procedures of the Experience Sampling Method (ESM; Csikszentmihalyi \& Larson, 1987; Hormuth, 1986). There were seven signals per day; one occurred at a random time within every 2-hour block of time between 7:30 a.m. and 9:30 p.m. The selfreport form, which required about 2 min to complete, asked about the student's situation and internal state at the moment immediately prior to each signal.

Participants responded to $84 \%$ of the signals they were eligible to receive by filling out a self-report; this provided an average of 38 reports per person. Separate analyses indicated that the missed signals occurred across a wide range of contexts and for a variety of reasons; however, there was an indication that missed signals were somewhat more likely during sports and socializing away from home (Larson, in press).

Students received a 40-min training session before they began the week of paging. At the end of the week, students filled out a series of questionnaires and took part in an interview, after which they received $\$ 8.00$ as a payment for participation.

\section{Measures}

Depression. Depression was assessed using the CDI, which was administered as apart of the questionnaires. The CDI is a 27 -item, self-report scale that quantifies symptoms including "mood and hedonic capacity, vegetative functions, self-evaluation, and interpersonal behaviors" (Kovacs, 1983, p. 5). Its readability has been assessed at fourth-grade level by some investigators (Berndt, Schwartz, \& Kaiser, 1983) and at the first-grade level by others (Kazdin \& Petti, 1982). Prior research shows the scale to correlate strongly with clinical interview measures of depression (Carlson \& Cantwell, 1979; Garber, 1984) and to discriminate normal children from hospitalized children (Saylor, Finch, Spirito, $\&$ Bennett, 1984) and depressed children from children with other diagnoses (Kovacs, 1983, 1985; Nelson et al., 1987; O’Leary \& Johnson, 1986; Saylor, Finch, \& McIntosh, 1988).

Consistent with the recommendations of Burbach, Farha, and Thorpe (1986), responses to the CDI were reviewed shortly after it was filled out. In several instances, when a child's total pattern of responses raised severe concern about his or her mental health, we spoke to the child, then contacted parents and facilitated arrangements for appropriate counseling. In designing the study, we decided to alter one item on the CDI that we felt placed an ethical obligation on us that conflicted with our initial promise to the students that their responses to individual items would be kept confidential. The item "I frequently feel like killing myself" was altered to "I frequently feel like harming myself." The mean score for this slightly revised scale was $9.46(S D=6.81$; range $=0-37)$. The standardized item alpha coefficient was .87 and .79 for the preadolescent boys and girls, respectively, and .90 and .89 for the young adolescent boys and girls, respectively.

To facilitate multivariate data analyses, we dichotomized depression scores; those subjects with a score of 12 or more constituted a depressed subgroup. This relatively low cut-off was dictated by a desire to avoid singularity in any of the cells of the four-way, multivariate analyses of variance (MANOVAS) to be performed. Kovacs (1983) reports that a cut-off of 12 catches $62 \%$ of diagnostically depressed cases and includes
$32 \%$ false positives. In instances when CDI scores were used as a linear variable, they were first transformed using a square root function in order to achieve a normal distribution.

Subjective states. Each time they were signaled, participants rated their subjective states on fixed-format items, including six 7-point semantic differential mood items and four 10-point ratings of attention and motivation used in prior research with the ESM (Csikszentmihalyi \& Larson, 1987; prior analyses showing age trends in the mean responses to these six semantic differential items were reported in Larson and Lampman-Petraitis [1989].) In addition, they responded to a checklist of feeling states similar to those used by Nowlis (1965) in the Mood Adjective Check List. These 24 items rotated on differing versions of the ESM sheet; each item was rated for half of the ESM reports.

To reduce the number of variables considered, we first selected a subset of 21 items that dealt with symptoms of depression identified by $D S M-I I I-R$ and other diagnostic schemes. For each individual we then computed aggregate scores for each item. (For the scales, these were means; for the checklist items, they were percentages, adjusted according to each person's overall rate of checking these items and then transformed with a square root function.) We then subjected these scores to factor analysis. Varimax and oblique rotations indicated four consistent factors. The first formed a scale of affect $(\alpha=.89)$, consisting of three semantic differential items (happy-unhappy, friendly-angry, cheerful-irritable). The second formed a scale of social feeling states $(\alpha=.86)$, on the basis of 7 checklist items (lonely, ignored, worried, nervous, accepted, proud, great; percentages for the first four were given a negative valence). The third formed a scale of psychological investment $(\alpha=.52)$, including two 10-point scales (with items such as, "How well were you paying attention?" and "Do you wish you had been doing something else?) and one checklist item (interested). The fourth formed a scale of energy $(\alpha=.72)$, including two semantic differential items (alert-drowsy, strong-weak) and one checklist item (tired).

In addition to considering mean scores for these four scales, we included a measure of emotional variability, computed as the standard deviation of the affect scale for each individual. These scores were orthogonal to the mean scores for the affect scale, $r(406)=.00$. They also were internally consistent from the first half to the second half of each participant's week of reporting (Larson, in press). Variability of social feeling states, psychological investment, and energy were not evaluated because these are not discussed in the depression literature.

To summarize, the five subjective-state scales we evaluated are affect, emotional variability, social feeling states, psychological investment, and energy level. The statistical distributions for all of these variables .were approximately normal and thus required no transformation. To standardize reporting of findings, after computing each scale from the raw items, we converted these values to a $z$-score scale.

Social context. Companionship at the time of each signal was evaluated by a fixed-format item on the ESM form that asked, "Who were you with?" Nearly all (98.8\%) of responses to this item are grouped into four basic categories: (1) With family includes all occasions with family members; (2) with friends includes times with friends both in and out of school (because prior research by Csikszentmihalyi and Larson, 1984 , showed that occasions when adolescents are with family members and friends jointly elicit moods similar to those experienced with friends alone, this subcategory is also included here); (3) in class includes times at school when participants marked being in class; and (4) alone includes times when they marked being "alone, no one around" ( $8 \%$ of all signals) and times when they marked being "alone, someone nearby" (12\%).

These ratings of social context were used to compute several measures. First, we used the raw frequencies to compute estimates of the amount of time each student spent in the different contexts. Because

${ }^{2}$ Prior analyses showing age trends in the mean responses to these six semantic differential items were reported in Larson and Lampman-Petraitis (1989). 
these percentages were normally distributed, no transformation was used.

Second, we calculated each person's average scores on the affect scale when he or she was in each context. These provide an estimate of what each individual typically experienced in that social environment. Context-specific scores were also computed for two additional self-report items. On each ESM self-report form, participants were asked to rate whether the people they were with were friendly or unfriendly, using a 7-point semantic differential scale. Average responses to these items provide information on how friendly each person perceived family, friends, and classmates to be. Students also responded on each ESM form to the question: "Would you rather have been: ( ) alone ( ) with people?" The percentages of time a person reported preferring to be alone in each social context were computed and a square root transformation was used to normalize distributions for the derived variables.

Other context and time-allocation variables. On the ESM form, participants were also asked to respond to open-ended questions asking what they were doing at the time of each random signal, where they were, and what they were thinking about. Responses have been coded into mutually exclusive coding categories. Reports on what participants were doing were coded into 127 categories, which have been collapsed into 13 basic categories of activity (classwork, homework, extracurricular activities, eating, transportation, personal care, chores and errands, media use, socializing, sports, idling, and other leisure; interrater agreement $=94 \%$ ). A small number of occasions when no activity was reported $(0.9 \%)$ and when participation in the study was reported as the activity $(0.7 \%)$ were coded as missing. Grade and sex trends in the students' activities have been reported in Larson and Richards (1989).

Reports on participants' location were coded into 68 categories, which have been collapsed into four basic categories (school; public; bedroom; and home, not in bedroom; interrater agreement $=99 \%$ ). Reports on what participants were thinking about were coded into 169 categories, which have been collapsed into eight thought-content categories (school, friends, family, media, sports, other leisure, maintenance activities, and nothing; interrater agreement $=98 \%$ ). Missing values were assigned for occasions when no thoughts were reported (3.5\%) and when the study was the topic of their thoughts $(2.0 \%)$.

For each of these categories of activity, location, and thoughts, we computed the percentage of times that category occurred for each individual. These percentages served as estimates of the amount of time the person spent in that category (e.g., how often he or she spent doing homework). A square root transformation was used to normalize these percentages.

The age-group division. Preliminary analyses indicated that school grade rather than age provided stronger differentiation of trends in the data. It appears that the ranking of "social age," as defined by the schools' grading system, rather than chronological age, defined by date of birth, is most significant to these youths' daily experience. Hence we have grouped the fifth and sixth graders, who are in elementary school, into the preadolescent category, and the seventh to ninth graders, who attend junior and senior high school, into the young adolescent age group. It should be noted that the young adolescent group is larger, hence estimates for this age group can be assumed to be somewhat more stable.

\section{Results}

Mean depression scores were higher for older students and those in the working class community. A three-way analysis of variance (ANOVA; sex, age, and community) indicated significant main effects for grade, $F(1,396)=9.22, p=.003$, and community, $F(1,396)=10.93, p<.001$. Older students and students from the working class community reported more depression. In addition, community and sex interacted, $F(1,396)=4.74, p$ $=.03$, with working class boys reporting the highest depression scores and middle class boys the lowest. The interaction between grade and sex that is commonly found in the literature (higher depression scores among older girls) was also suggested but was not significant, $F(1,396)=2.57, p=.11$. To control for these differences in rates of depression, in subsequent analyses we include sex, grade and community, along with depression, as factors in all analyses.

\section{Daily States Associated With Depression}

In order to evaluate the overall relationship between depression and daily subjective states, a multiple analysis of variance (MANOVA) was conducted using scores for the five subjectivestate scales as dependent variables and depression, sex, grade, and community as factors. All of the dependent variables in this and subsequent analyses were first subjected to homogeneity of variance tests, which indicated that MANOVA would be acceptable. Only significant or close-to-significant MANOVA effects were followed up with univariate tests.

The MANOVA for subjective states revealed significant main effects for depression, multiple $F(5,376)=7.79, p<.001$; grade, multiple $F(5,376)=7.16, p<.001$; and sex, multiple $F(5,376)$ $=11.07, p<.001$; and a significant interaction between depression and grade, multiple $F(5,376)=2.84, p=.016$. The sex difference was attributable to univariate trends for the variables affect and emotional variability, which were higher for girls, and energy, which was higher for boys. Table 1 displays the depression and grade effects.

These findings indicate that depressed youths experienced different average daily subjective states than nondepressed youths. The univariate tests showed that depressed youngsters reported more negative scores on all five subjective state variables. It should be noted that Roy-Bargmann stepdown significance tests indicate that these effects are not independent of each other (at least not at the person level at which this analysis was conducted). These stepdown tests, carried out in the order of the variables displayed in the table, indicate significance for only affect, $F(1$, $376)=18.43, p<.001$, and emotional variability, $F(1,376)=$ $7.93, p=.005$, suggesting that two underlying person-level variables account for the differences.

The multivariate interaction found between depression and grade indicates that the pattern of subjective states associated with depression is more pronounced in the older age group. An examination of Table 1 suggests that among preadolescents, the differences in subjective states that distinguish depressed children are quite small. Indeed, in a separate regression analysis, the association between depression and these subjective state measures was minimal for this younger age group (adjusted $R^{2}$ $=.07)$. Within the older age group, the differences between depressed and nondepressed were much larger $\left(R^{2}=.18\right)$. The univariate tests for the depression by grade interaction indicated significance only for social feeling states and marginal significance for psychological investment, which suggests that these two variables account for the bulk of the age difference. It appears that as youths enter adolescence, depression becomes associated with a 
Table 1

Mean Daily Psychological States of Depressed and Nondepressed Youth by Age

\begin{tabular}{|c|c|c|c|c|c|c|c|}
\hline \multirow[b]{3}{*}{ Variable } & \multicolumn{4}{|c|}{ Group } & & & \\
\hline & \multicolumn{2}{|c|}{ Preadolescent } & \multicolumn{2}{|c|}{ Young adolescent } & \multicolumn{3}{|c|}{ Univariate $F$} \\
\hline & $\begin{array}{c}\text { Not } \\
\text { depressed }\end{array}$ & Depressed & $\begin{array}{c}\text { Not } \\
\text { depressed }\end{array}$ & Depressed & Depression & Age & $\begin{array}{c}\text { Depression } X \\
\text { Age }\end{array}$ \\
\hline Affect & .32 & -.02 & .04 & -.54 & $18.43^{* * *}$ & $15.24^{* * *}$ & 1.55 \\
\hline Emotional variability & -.20 & .12 & -.02 & .27 & $4.75^{*}$ & 0.38 & 1.28 \\
\hline Social states & .27 & .24 & .06 & -.61 & $7.29 * *$ & $23.34^{* * *}$ & $7.75^{* *}$ \\
\hline Psychological investment & .26 & .20 & .00 & -.48 & $5.37^{*}$ & $16.70^{* * *}$ & $2.89+$ \\
\hline Energy & .25 & .10 & -.07 & -.30 & $4.09^{*}$ & $6.45^{*}$ & 0.06 \\
\hline$n$ & 125 & 42 & 145 & 87 & & & \\
\hline
\end{tabular}

Note. Means scaled on a $z$-score scale.

$\dagger p<.10 .^{*} p<.05 .^{* *} p<.01 .^{* * *} p<.001$.

stronger pattern of distinct daily states. In a further analysis, we examined whether the lower average affect of depressed students was attributable to less positive affect or more negative affect. For all individuals, we computed the percentage of times they rated their affect as negative and the percentage of times they rated their state as extremely positive on the three affect items (cf. Larson, 1987). Given that the majority of ratings on these items were in the neutral and mildly positive range of the scales, these two sets of percentages were only moderately correlated $(r=-$ .33). In four-way ANOVAS with sex, grade, community, and depression as the factors, significant main effects occurred for both positive affect, $F(1,384)=4.85, p=.028$, and negative affect, $F(1,384)=22.57, p<.001$. For depressed students, extreme positive affect was reported for only $16 \%$ of the times, as compared to $24 \%$ for nondepressed, and negative affect was reported for $19 \%$ of the times, as compared to $12 \%$ for the nondepressed students. A significant two-way interaction between depression and community, $F(1,384)=4.38, p=.037$, suggested that negative affect was more strongly associated with depression in the working class community.

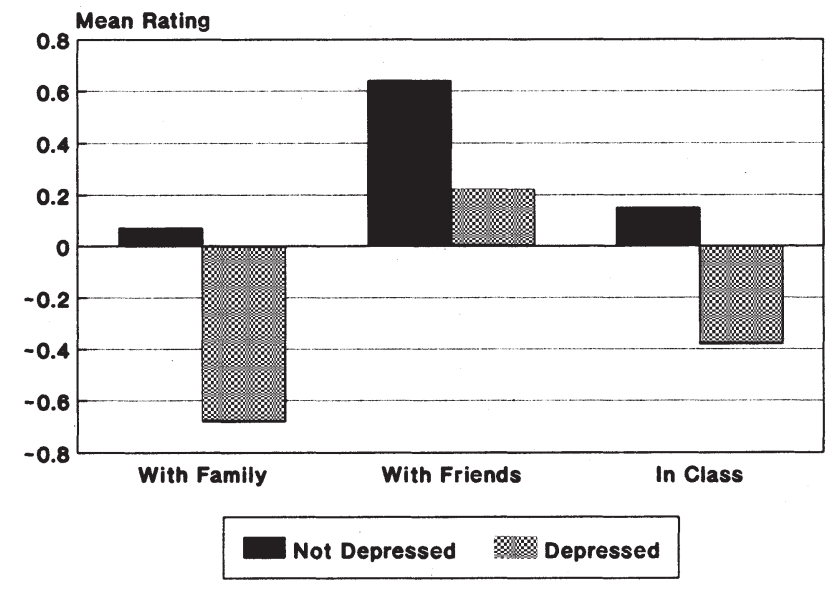

Figure 1. Perceived friendliness of others by social context.

\section{Experience in Daily Social Contexts}

The next question is whether these negative states are equally distributed across contexts or whether they might be localized in one social domain. To evaluate this question, we focused on affect, analyzing the means for each individual in each social context. A repeated-measures MANOVA was carried out with depression, grade, gender, and community as between-person factors and social context as the repeated within-person factor. (Because the other variables included the checklist items, which occurred only on every other self-report form, it was more difficult to obtain accurate estimates for these scales in each social context. Exploratory analyses using the energy and investment scales without the checklist items suggested findings similar to those obtained for the affect scale.) In this analysis, all of the students who took part during the summer were excluded, because they had no data for time in class, and a few other students who had no reports in one of the four contexts were also excluded. No significant interaction was found between depression and context, $F(3,888)=.84, p=.474$, and no higher-order interactions emerged. This suggests that the negative affect associated with depression occurred across social contexts. Similar repeated-measures MANOVAS were also conducted with the students' ratings of the friendliness of the people they were with and their reports on whether they preferred to be alone or with others. For the ratings of friendliness, we evaluated their mean ratings in three contexts (family, friends, and class; the item did not apply when they were alone). This MANOVA yielded a significant main effect for depression, $F(1,304)=26.09, p<.001$. Compared with nondepressed youths, depressed individuals rated others as less friendly across social contexts. A marginally nonsignificant interaction

\footnotetext{
${ }^{3}$ Because the other variables included the checklist items, which occurred only on very other self-report form, it was more difficult to obtain accurate estimates for these scales in each social context. Exploratory analyses using the energy and investment scales without the checklist items suggest findings similar to those obtained for the affect scale.
} 


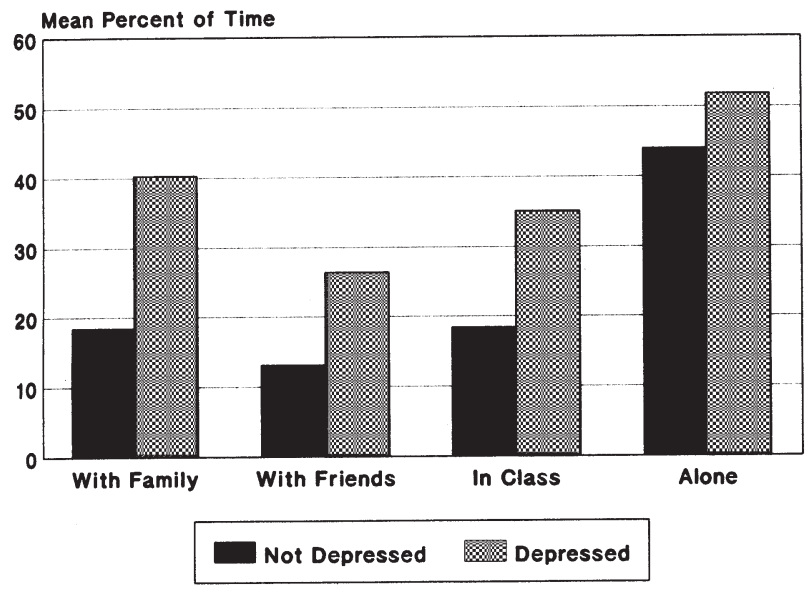

Figure 2. Rate of wanting to be alone by social context.

between depression and context, $F(2,608)=2.46, p=.086$, suggested that family members were perceived as the least friendly (Figure 1).

Depressed and nondepressed youngsters also differed in their rate of wanting to be alone and in the contexts where they reported wanting to be alone (Figure 2). The four-way, repeatedmeasures MANOVA conducted with this dependent variable produced a significant main effect for depression, $F(1,228)=15.92$, $p<.001$, and a significant interaction between depression and social context, $F(3,684)=2.83, p=.038$. To identify which contexts contributed to the interaction, we used deviation contrasts in the MANOVA, comparing effects for each of the first three contexts with the overall mean. These showed a significant univariate $F$ for preferring to be alone when with the family, $F(3,226)=$ $4.30, p=.039$, and a marginally nonsignificant trend for wanting to be alone when in class, $F(3,226)=3.48, p=.064$. This finding is consistent with the finding for perceived friendliness in sug- gesting that the family setting may be a particularly aggravated context for depressed youth.

\section{Differences in How Time is Spent}

These findings lead to the question of whether depressed children spend their time differently than do nondepressed children. Given their greater expressed desire to be alone, do depressed youths spend their time with different companions, or in different activities? Because the ESM signals occurred at random, the selfreports provide estimates of how each participant's daily hours were typically passed. We examined who they spent their time with, what they spent their time doing, and where they spent their time.

Our strategy for evaluating these variables was similar to that used above, using estimates of time allocation as the dependent variables in a four-way MANOVA having depression, grade, sex and community as the factors. The first analysis, examining time spent in different social contexts, used the percentages of time spent with family, with friends, and alone as the dependent variables. This analysis yielded no main effect for depression, but did reveal a close-to-significant interaction between sex and depression, $F(3,387)=2.38, p=.069$. The univariate tests indicated no differences in the amount of time spent alone or with family members. The major difference was for time spent with friends, which was approximately the same for both groups of girls, but nondepressed boys spent much more time with friends than depressed boys.

Figure 3 shows this difference, with time spent with friends disaggregated by subcategories of friendship groups. This figure suggests that depressed boys' deficit in time with friends is attributable to three categories. They spent about half as much of their time with one friend of the same sex, with same-sex groups, and in situations in which they were jointly with friends and family members. In order to test these relationships, the percentage of time each child reported in all six subcategories of friendship

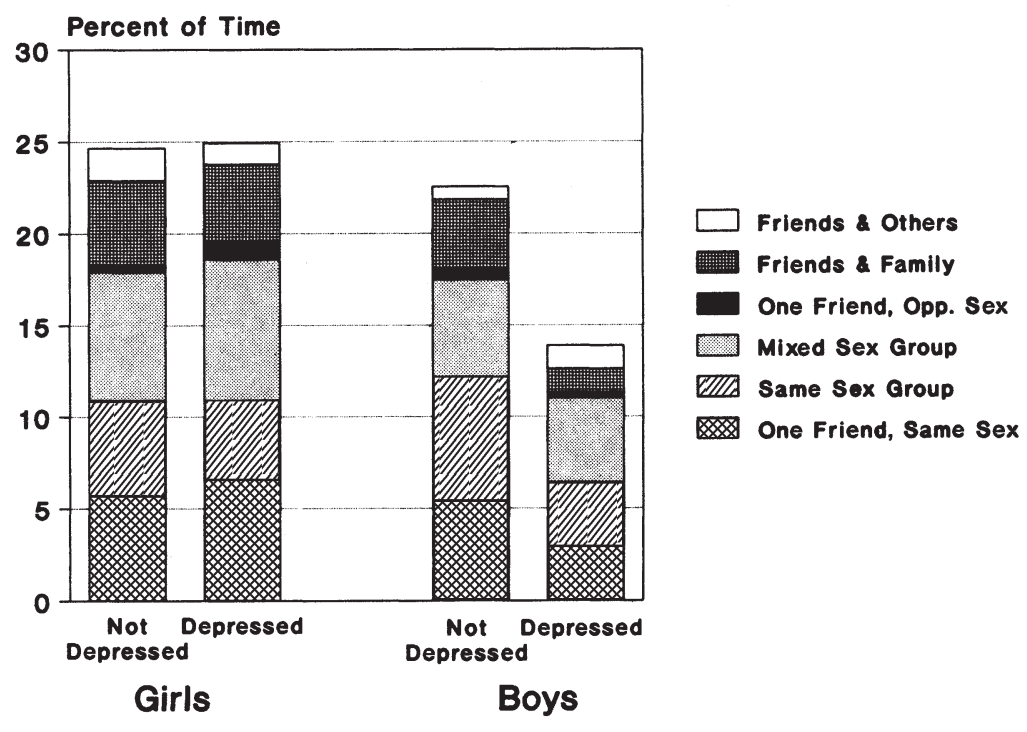

Figure 3. Amount of time spent with friends (Opp. = opposite). 
Table 2

Mean Percentage of Time Reported With Different Subcategories of Friends for Depressed and Non-depressed Girls and Boys

\begin{tabular}{|c|c|c|c|c|c|c|}
\hline \multirow[b]{3}{*}{$\begin{array}{c}\text { Friend subcategory/ } \\
\text { age group }\end{array}$} & \multirow{2}{*}{\multicolumn{2}{|c|}{ Girls }} & \multirow{2}{*}{\multicolumn{2}{|c|}{ Boys }} & \multicolumn{2}{|c|}{ Univariate $F$} \\
\hline & & & & & \multirow{2}{*}{$\begin{array}{c}\text { Sex } X \\
\text { Grade } X \\
\text { Depression }\end{array}$} & \multirow[b]{2}{*}{$\begin{array}{c}\text { Sex } \times \\
\text { Depression } \\
\end{array}$} \\
\hline & $\begin{array}{c}\text { Not } \\
\text { depressed }\end{array}$ & Depressed & $\begin{array}{c}\text { Not } \\
\text { depressed }\end{array}$ & Depressed & & \\
\hline \multicolumn{7}{|l|}{$\begin{array}{l}\text { One friend, same } \\
\text { sex }\end{array}$} \\
\hline Preadolescent & 6.20 & 3.86 & 5.11 & 2.51 & 0.39 & $7.22 * *$ \\
\hline Adolescent & 5.14 & 7.44 & 5.66 & 3.26 & & \\
\hline Total & 5.67 & 6.56 & 5.43 & 2.95 & & \\
\hline \multicolumn{7}{|l|}{ Group, same sex } \\
\hline Preadolescent & 5.35 & 4.45 & 6.47 & 2.86 & 0.35 & $3.19 \dagger$ \\
\hline Adolescent & 5.02 & 4.28 & 6.96 & 3.88 & & \\
\hline Total & 5.18 & 4.33 & 6.76 & 3.46 & & \\
\hline \multicolumn{7}{|l|}{$\begin{array}{l}\text { One friend, opposite } \\
\text { sex }\end{array}$} \\
\hline Preadolescent & 0.40 & 0.00 & 0.08 & 0.42 & $6.19^{*}$ & 0.04 \\
\hline Adolescent & 0.49 & 1.15 & 0.88 & 0.22 & & \\
\hline Total & 0.45 & 0.87 & 0.54 & 0.30 & & \\
\hline \multicolumn{7}{|l|}{ Mixed sex group } \\
\hline Preadolescent & 6.43 & 4.31 & 5.23 & 3.93 & 0.43 & 0.99 \\
\hline Adolescent & 7.63 & 8.79 & 5.37 & 5.10 & & \\
\hline Total & 7.04 & 7.69 & 5.31 & 4.62 & & \\
\hline \multicolumn{7}{|l|}{$\begin{array}{l}\text { Friends and others, } \\
\text { jointly }\end{array}$} \\
\hline Preadolescent & 2.43 & 0.27 & 0.57 & 2.30 & $10.52^{* * *}$ & $7.17 * *$ \\
\hline Adolescent & 1.08 & 1.43 & 0.82 & 0.56 & & \\
\hline Total & 1.75 & 1.15 & 0.71 & 1.27 & & \\
\hline \multicolumn{7}{|l|}{$\begin{array}{l}\text { Family and friends, } \\
\text { jointly }\end{array}$} \\
\hline Preadolescent & 4.74 & 6.23 & 4.79 & 1.00 & 1.53 & $4.22 *$ \\
\hline Adolescent & 4.46 & 3.63 & 3.04 & 1.51 & & \\
\hline Total & 4.60 & 4.27 & 3.78 & 1.30 & & \\
\hline
\end{tabular}

$\dagger p<.10 .^{*} p<.05 . \quad{ }^{* *} p<.01 . \quad{ }^{* * *} p<.001$.

groups was computed and these percentages were subjected to a square root transformation to normalize the distributions. A fourway, Depression $\times$ Grade $\times$ Sex $\times$ Community MANOVA was then conducted with the amount of time spent in each of the six subcategories as the six dependent variables. A significant twoway interaction was found between sex and depression, $F(6,384)$ $=3.23, p=.004$; and a three-way interaction between sex, grade, and depression, $F(6,384)=3.33, p=.003$. Table 2 displays the mean values for these analyses.

Consistent with the impressions drawn from Figure 3, the univariate $F$ tests for this MANOVA show that depressed boys spent significantly less time with same-sex friends and with friends and family members jointly. On the other hand, they appeared to spend more time with friends when others (teachers, recreational leaders, etc.) are present, a pattern that is part of a more complex interaction with sex and grade. It is also worth noting that for depressed boys, there was no age increase in the amount of time spent with a single member of the opposite sex, although for depressed girls there was such an increase.

The daily activities associated with depression were examined with another four-way MANOVA that used the percentages of time in the 13 categories of activity as the multivariate dependent variable. The main effect for depression was not significant, $F(13,378)=1.12, p=.339$, nor were any of the higher order interactions. Given subsequent findings, however, it is worth noting that there was a strong univariate effect for amount of time spent playing sports, $F(1,378)=8.41, p=.004$. Depressed individu-

Table 3

Mean Percentage of Time Depressed and Nondepressed Youth Reported Being in Different Daily Environments

\begin{tabular}{lccc}
\hline & \multicolumn{2}{c}{ Group } & \\
\cline { 2 - 3 } \multicolumn{1}{c}{ Environment } & $\begin{array}{c}\text { Not } \\
\text { depressed }\end{array}$ & Depressed & Univariate $F$ \\
\hline School & 32.3 & 35.2 & 0.65 \\
Public & 22.3 & 17.8 & $7.30^{*}$ \\
Bedroom & 9.8 & 12.4 & $6.69^{*}$ \\
At home, not bedroom & 37.6 & 32.5 & 0.02 \\
\hline
\end{tabular}

${ }^{*} p<.01$. 
Table 4

Mean Percentage of Times Depressed and Nondepressed Youth Reported Thinking About Different Topics

\begin{tabular}{lccc}
\hline & \multicolumn{2}{c}{ Group } & \\
\cline { 2 - 3 } \multicolumn{1}{c}{ Topic } & $\begin{array}{c}\text { Not } \\
\text { depressed }\end{array}$ & Depressed & Univariate $F$ \\
\hline School & 24.6 & 23.8 & 0.00 \\
Friends & 11.1 & 11.8 & 1.21 \\
Family & 5.0 & 6.3 & $3.82^{*}$ \\
Media & 7.3 & 8.1 & 0.34 \\
Sports & 13.4 & 9.1 & $11.81^{* *}$ \\
Other leisure activities & 14.1 & 16.1 & 0.69 \\
Maintenance activities & 12.3 & 11.9 & 0.02 \\
Nothing & 12.2 & 12.9 & 1.85 \\
\hline
\end{tabular}

$* p<.05 . \quad{ }^{* *} p<.001$.

als reported involvement in sports for an average of 5.2 percent of the times they were signaled, whereas nondepressed reported playing sports for 7.3 percent. A similar MANOVA for the four categories of location yielded a significant main effect for depression, $F(4,386)=3.40, p=.010$, and no higher-order interactions. Table 3 shows that depressed individuals spent less time in public locations and more time in their bedrooms.

\section{Daily Thoughts}

Topics of thought were analyzed using the same four-way MANOVA design, with percentages for the eight thought categories as the dependent variables. A significant main effect was found for depression, $F(8,382)=2.49, p=.012$. Univariate significance tests, reported in Table 4 , indicated that depressed individuals thought more often about their families and less often about sports.

\section{Discussion}

The objective of this study was to describe the daily psychological states and time-use patterns associated with depression within a representative cross-section of preadolescents and young adolescents. Because the study dealt with a nonclinical sample and used a quite liberal cut-off for identifying depression, findings should be interpreted as indicative only of patterns associated with depressive tendencies; conclusions might differ for a more narrowly defined group of youths having major depression. Table 5 summarizes the findings.

\section{Daily Psychological States}

Depressed individuals within this population reported experiencing different average levels on a range of psychological state variables: they reported less positive average affect, more negative social feeling states, less psychological investment in whatever they were doing, and lower energy levels across the hours of the day. They also showed greater variability in their affect across self-reports. These findings demonstrate a correspondence between the CDI and daily reports of subjective states. They indi- cate that symptoms of depression identified on a global measure of depression correspond to what youths actually experience in daily life.

Substantial age differences were found in the strength of these associations. The relationship between depression scores and daily subjective states was much greater for the older members of the sample, the seventh to ninth graders, than for the younger fifth and sixth graders. Our data and those of others (e.g., Smucker, Craighead, Craighead, \& Green, 1986) do not indicate that the CDI is any less reliable for this younger age group; nor are we aware of any findings indicating that it is less valid in making discriminations. Nonetheless, there appears to be a much weaker correspondence between CDI scores and daily affect for this younger age group.

One explanation might be that preadolescents as a whole are less able to identify negative affect. Developmental research indicates that the onset of adolescence is associated with more sophisticated conceptions of emotion (Cicchetti \& SchneiderRosen, 1986; Harris, Olthof, \& Terwogt, 1981; Weiner \& Graham, 1984). A related possibility is that there is a "developmental lag" in the ability of depressed children to label their internal states (Cicchetti \& Schneider-Rosen, 1986; Kovacs, 1986). Carlson and Garber (1986) report that depressed children are less likely to verbalize sadness even though they appear sad and tearful. Another possibility is that negative affect is less frequent and pervasive in depressed children than in depressed adolescents. Ushakov and Girich (1972) found depressive symptoms to be less persistent and less readily recognized in younger subjects. Garber (1984) found fewer affective symptoms among preadolescent girls than among adolescent girls. Additional research is needed to distinguish between these alternatives. For the time being, it should be recognized that subjective-state measures may be a less adequate means of identifying depression in preadolescence.

\section{The Daily Contexts of Depression}

In general, we were struck by how few associations there were between depression and how children and young adolescents experienced the different contexts of their lives. Outwardly, the daily patterns of depressed children and adolescents are quite like those of nondepressed peers. They did not spend more time alone, as might have been expected. No significant differences were found in what depressed boys and girls spent their time doing, and there were few differences in what they reported thinking about. These findings suggest that many depressed youths at least go through the motions of living a life just like anyone else.

The few differences that emerge, however, are important and bespeak the possibility of increasing social isolation as these youths grow older. Depressed individuals in the study spent less time in public and more time in their bedrooms. They perceived others as less friendly, particularly family members, and more often felt that they wanted to be alone, again especially when they were with family members.

Finally, depressed boys, but not depressed girls, spent much less time with friends, including half as much time with friends 
Table 5

Differences in Daily Experiences Associated With Depression: Summary of Main Effects and Interactions

\begin{tabular}{|c|c|c|c|}
\hline Dependent variable & Main effects for depression & Sex $\times$ Depression interaction & Grade $\times$ Depression interaction \\
\hline Subjective states & $\begin{array}{l}\text { Depressed report (a) more frequent } \\
\text { negative affect, (b) less frequent } \\
\text { positive affect, (c) more variable } \\
\text { affect, (d) more negative social } \\
\text { affect, (e) lower psychological } \\
\text { investment, (f) lower energy. }\end{array}$ & $n s$ & $\begin{array}{l}\text { Depressed young adolescents report } \\
\text { more negative social affect and } \\
\text { lower investment than do } \\
\text { depressed preadolescents. }\end{array}$ \\
\hline Affect by context & $n s$ & $n s$ & $n s$ \\
\hline Preferring to be alone & $\begin{array}{l}\text { Depressed want to be alone more } \\
\text { often, especially when they are } \\
\text { with their families. }\end{array}$ & $n s$ & $n s$ \\
\hline Companionship & $n s$ & $\begin{array}{l}\text { Depressed boys spend less time with } \\
\text { friends than nondepressed boys. }\end{array}$ & $n s$ \\
\hline Activities & $n s$ & $n s$ & $n s$ \\
\hline Location & $\begin{array}{l}\text { Depressed spend less time in public, } \\
\text { more time in their bedrooms. }\end{array}$ & $n s$ & $n s$ \\
\hline Thoughts & $\begin{array}{l}\text { Depressed think more about their } \\
\text { families, less about sports. }\end{array}$ & $n s$ & $n s$ \\
\hline
\end{tabular}

Note. No interactions with community and no three-way interactions of depression, sex, and grade were found.

of the same sex and in situations with both family members and friends present.

This sex difference in amount of time with friends deserves particular attention. First, it should be noted that no sex differences emerged in how depressed boys versus depressed girls felt when they were with their friends. Depressed girls appeared to experience as much subjective social isolation as depressed boys. The difference is that for boys, but not girls, these subjective feelings corresponded with an objective reality. Second, it is important to note that depressed and nondepressed individuals spent the same amount of time thinking about friends. The finding that depressed boys thought about friends as much as nondepressed boys (7.7\% of signals vs. $8.8 \%$ ) suggests that friends are important to them and that their lower rate of peer interaction is not voluntary. The greater aggression and antisocial behavior that Gjerde et al. (1988) found among depressed boys suggests that boys may externalize depression in a way that leads to rejection by peers. Alternately, it may be the depression itself that alienates potential friends. Whereas girls learn to share both positive and negative feelings with each other (Nolen-Hoeksema, 1987), a sharing that may provide the basis for continuing association, for boys, overt expression of negative affect may be unaccepted, off-putting, and destructive to friendship.

The less frequent involvement in sports among depressed individuals is also worthy of note. Particularly among boys, sports are a major activity shared with same-sex friends (Kirshnit, Ham, \& Richards, in press), thus their lesser time in playing sports is interrelated with their social isolation. It is also important to note that participation in sport is typically associated with very positive mood states and thus may make an important contribution to the hedonic level of normal children (Chalip, Csikszentmih- alyi, Kleiber, \& Larson, 1983; Kirshnit et al., in press). The relative absence of sports in the lives of depressed youths, therefore, might be seen as a contributor to their lower average affect.

In sum, the findings of this study provide some clues about the adjustment of depressed individuals to daily life, clues that might be useful for identifying depression, designing interventions, and directing future research. We have found, first, that self-reported affect appears to be a less useful sign of depression for preadolescents than for adolescents. Second, although negative affect was reported across all contexts, there were suggestions in these data that the family is often the context of greatest discomfort. Third, the findings suggest that objective social isolation may be a more frequent correlate and defining criterion of depression for boys than for girls. Finally, whereas daily patterns of activity and thought are generally unassociated with depression, involvement in sports stands out as a clear correlate of psychological health, suggesting that interventions that encouraged sports involvement in depressed youth might have a beneficial effect.

\section{References}

American Psychiatric Association. (1980). Diagnostic and statistical manual of mental disorders (3rd ed.). Washington, DC: Author.

American Psychiatric Association. (1987). Diagnostic and statistical manual of mental disorders (Rev. 3rd ed.). Washington, DC: Author.

Asarnow, J. R., Carlson, G. A., \& Guthrie, D. (1987). Coping strategies, self-perceptions, hopelessness, and perceived family environments in suicidal children. Journal of Consulting and Clinical Psychology, 55, 361-366. 
Bernard, H., Killworth, P., Kronenfeld, D., \& Sailer, L. (1984). On the validity of retrospective data: The problem of informant accuracy. Annual Review of Anthropology, 13, 495-517.

Berndt, D., Schwartz, S., \& Kaiser, C. (1983). Readability of self-report depression inventories. Journal of Consulting and Clinical Psychology 51, 627-628.

Blatt, S. J., D’Afflitti, J. P., \& Quinlan, D. M. (1976). Experiences of depression in normal adults. Journal of Abnormal Psychology, 85, 383-389.

Burbach, D., \& Borduin, C. (1986). Parent-child relations and the etiology of depression: A review of methods and findings. Clinical Psychology Review, 6, 133-153.

Burbach, D., Farha, J., \& Thorpe, J. (1986). Assessing depression in community samples of children using self-report inventories: Ethical considerations. Journal of Abnormal Child Psychology, 14, 579-589.

Carlson, G. A., \& Cantwell, D. P. (1979). A survey of depressive symptoms in a child and adolescent psychiatric population. American Academy of Child Psychiatry 18, 587-599.

Carlson, G. A., \& Garber, J. (1986). Developmental issues in the classification of depression in children. In M. Rutter, C. Izard, \& P. Read (Eds.), Depression in young people: Developmental and clinical perspectives (pp. 399-434). New York: Guilford.

Chalip, L., Csikszentmihalyi, M., Kleiber, D., \& Larson, R. (1983). Variations of experience in formal and informal sport. Research Quarterly for Exercise Sport, 55, 109-116.

Cicchetti, D., \& Schneider-Rosen, K. (1986). An organizational approach to childhood depression. In M. Rutter, C. Izard, \& P. Read (Eds.), Depression in young people: Developmental and clinical perspectives (pp. 71-134). New York: Guilford.

Csikszentmihalyi, M., \& Larson, R. W. (1984). Being adolescent. New York: Basic Books.

Csikszentmihalyi, M., \& Larson, R. W. (1987). The Experience Sampling Method. Journal of Nervous and Mental Disease, $175,526-536$.

deVries, M. (1987). Investigating mental disorders in their natural settings. Journal of Nervous and Mental Disease, 175, 509-513.

Garber, J. (1984). The developmental progression of depression in female children. In D. Cicchetti \& K. Schneider-Rosen (Eds.), Childhood depression (pp. 29-58). San Francisco: Jossey-Bass.

Gjerde, P. F., Block, J., \& Block, J. H. (1988). Depressive symptoms and personality during late adolescence: Gender differences in the externalization-internalization of symptom expression. Journal of Abnormal Psychology, 97, 475-486.

Gove, W. R., \& Herb, T. R. (1974). Stress and mental illness among the young: A comparison of the sexes. Social Forces, 52, 256-265.

Harris, P. L., Olthof, T., \& Terwogt, M. M. (1981). Children's knowledge of emotion. Journal of Child Psychology, 22, 247-261.

Hirschfeld, M. A., \& Cross, C. K. (1982). Epidemiology of affective disorders. Archives of General Psychiatry, 39, 35-46.
Hormuth, S. (1986). The sampling of experience in situ. Journal of Personality, 54, 262-293.

Inamder, S. C., Simopoulos, G., Osborn, M., \& Bianchi, E. C. (1979). Phenomenology associated with depressed moods in adolescents. American Journal of Psychiatry, 136, 156-159.

Izard, C., \& Schwartz, G. (1986). Patterns of emotion in depression. In M. Rutter, C. Izard, \& P. Read (Eds.), Depression in young people: Developmental and clinical perspectives (pp. 33-70). New York: Guilford.

Kandel, D. B., \& Davies, M. (1982). Epidemiology of depressive mood in adolescents. Archives of General Psychiatry, 39, $1205-1212$

Kandel, D. B., \& Davies, M. (1986). Adult sequelae of adolescent depressive symptoms. Archives of General Psychiatry, 43, 255-262.

Kashani, J. H., Beck, N. C., Hoeper, E. W., Fallahi, C., Corcoran, C. M., McAllister, J. A., Rosenberg, T. K., \& Reid, J. C. (1987). Psychiatric disorders in a community sample of adolescents. American Journal of Psychiatry, 144, 584-589.

Kashani, J. H., Carlson, G. A., Beck, N. C., Hoeper, E. W., Corcoran, C. M., McAllister, J. A., Fallahi, C., Rosenberg, T. K., \& Reid, J. C. (1987). Depression, depressive symptoms, and depressed mood among a community sample of adolescents. American Journal of Psychiatry, 144, 931-934.

Kazdin, A. E., \& Petti, T. A. (1982). Self-report and interview measures of childhood and adolescent depression. Journal of Child Psychology and Psychiatry, 23, 437-457.

Kirshnit, C., Ham, M., \& Richards, M. H. (in press). Athletic activities during early adolescence. Journal of Youth and Adolescence.

Kovacs, M. (1983). The Children's Depression Inventory: A selfrated depression scale for school-aged youngsters. Unpublished manuscript.

Kovacs, M. (1985). The Children's Depression Inventory. Psychopharmacology Bulletin, 21, 995-998.

Kovacs, M. (1986). A developmental perspective on methods and measures in the assessment of depressive disorders: The clinical interview. In M. Rutter, C. Izard, \& P. Read (Eds.), Depression in young people: Developmental and clinical perspectives (pp. 435-465). New York: Guilford.

Kovacs, M., \& Beck, A. (1977). An empirical-clinical approach toward a definition of childhood depression. In J. Schulterbrandt \& A. Raskin (Eds.). Depression in childhood: Diagnosis. treatment and conceptual models (pp. 1-26). Washington, DC: Department of Health, Education and Welfare.

Kovacs, M., Feinberg, T., Crouse-Novack, M., Paulauskas, S., \& Finkelstein, R. (1984). Depressive disorders in childhood. Archives of General Psychiatry, 41, 229-237.

Larson, R. (1987). On the independence of positive and negative affect within hour-to-hour experience. Motivation and Emotion, 11, 145-156.

Larson, R. (in press). Beeping children and adolescence: A method for studying time use and daily experience. Journal of Youth and Adolescence.

Larson, R., \& Lampman-Petraitis, C. (1989). Daily emotional 
states associated with the onset of adolescence. Child Development, 60, 1250-1260.

Larson, R., \& Richards, M. H. (1989). Daily companionship in childhood and adolescence: Changing developmental contexts. Unpublished manuscript.

Larson, R., \& Richards, M. H. (in press). The changing life space of early adolescence [special issue]. Journal of Youth and Adolescence.

Lefkowitz, M. M., \& Tesiny, E. P. (1980). Assessment of childhood depression. Journal of Consulting and Clinical Psychology, 48, 43-50.

McConville, B. J ., \& Bruce, M. A. (1985). Depressive illnesses in children and adolescents: A review of current concepts. Canadian Journal of Psychiatry, 30, 119-129.

Merrick, W. A. (1988). Dysphoric moods in normal and depressed adolescents. Unpublished doctoral dissertation, University of Chicago, Chicago, IL.

Nelson, W. M., Politano, P. M., Finch, A. J., Wendel, N., \& May hall, C. (1987). Children's Depression Inventory: Normative data and utility with emotionally disturbed children. Journal of the American Academy of Child and Adolescent Psychiatry, 26, 43-48.

Nolen-Hoeksema, S. (1987). Sex differences in unipolar depression: Evidence and theory. Psychological Bulletin, 101, 259282.

Nowlis, V. (1965). Research with the Mood Adjective Check List. In S. S. Tomkins \& C. E. Izard (Eds.), Affect, cognition. and personality (pp. 352-389). New York: Springer.

O’Leary, K. D., \& Johnson, S. B. (1986). Assessment and assessment of change. In H. Quay \& J. Werry (Eds.), Psychopathological disorders of childhood (3rd ed., pp. 423-454). New York: Wiley.

Petersen, A. C., Ebata, A., \& Sarigiani, P. (1987, April). Who expresses depressive affect in adolescence. Paper presented at the biennial meetings of the Society for Research in Child Development, Baltimore, MD.

Puig-Antich, J. (1982). Major depression and conduct disorder in prepuberty. Journal of the American Academy of Child Psychiatry, 21, 118-128.

Quay, H., \& LaGreca, A. (1986). Disorders of anxiety, withdrawal, and dysphoria. In H. Quay \& J. Werry (Eds.), Psychopathological disorders of childhood (3rd ed., pp. 73-110). New York: Wiley.
Rutter, M. (1986). Depressive feelings, cognitions, and disorders: A research postscript. In M. Rutter, C. Izard, \& P. Read (Eds.), Depression in young people: Developmental and clinical perspectives (pp. 491-519). New York: Guilford.

Saylor, C. F., Finch, A. J., \& McIntosh, J. A. (1988). Self-reported depression in psychiatric, pediatric, and normal populations. Child Psychiatry and Human Development, 18, 250-254.

Saylor, C. F., Finch, A. J., Spirito, A., \& Bennett, B. (1984). The Children's Depression Inventory: A systematic evaluation of psychometric properties. Journal of Consulting and Clinical Psychology, 52, 955-967.

Schwartz, R., \& Trabasso, T. (1984). Children's understanding of emotion. In C. Izard, J. Kagan, \& R. Zajonc (Eds.), Emotions, cognitions and behavior (pp. 409-437). Cambridge, England: Cambridge University Press.

Smucker, M. R., Craighead, W. E., Craighead, L. W., \& Green, B. J. (1986). Normative and reliability data for the Children's Depression Inventory. Journal of Youth and Adolescence, 14, 25-39.

Strober, M., \& Carlson, G. (1982). Bipolar illness in adolescents with major depression: Clinical, genetic, and psychopharmacologic predictors in a three-to-four-year prospective followup investigation. Archives of General Psychiatry, 39, 549555.

Ushakov, G. K., \& Girich, Y. P. (1972). Special features of psychogenic depression in children and adolescents. In A. Annell (Ed.), Depressive states in childhood and adolescence (pp. 510-516). Stockholm, Sweden: Almquist \& Wiksell.

Vredenburg, K., Krames, L., \& Flett, G. L. (1986). Sex differences in the clinical expression of depression. Sex Roles, 14, $37-$ 49.

Webb, T. E., \& VanDevere, C. A. (1985). Sex differences in the expression of depression: A developmental interaction effect. Sex Roles, 12, 91-95.

Weiner, B., \& Graham, S. (1984). An attributional approach to emotional development. In C. Izard, J. Kagan, \& R. Zajonc (Eds.), Emotions, cognitions and behavior (pp. 167-191). Cambridge, England: Cambridge University Press.

Submitted September 1988; Revised August 1989; Accepted August 1989. 